The IBP Handbook is a technical publication that outlines the methods to be used in the kinds of studies presented in the symposium. Its many sections are inevitably uneven in presentation and some give little detailed guidance to the worker in the field. In general, however, it provides the best starting point for anyone wanting to examine secondary productivity in large herbivores, and its sections range over such topics as energy flow, growth, age determination, metabolism and habitat manipulation.

P. A. JEWELL

\title{
Animals in the Night by J. H. Prince. Angus and Robertson, 40 s.
}

One of the many interesting points made by Professor Prince in this book is that the majority of wild animals are either nocturnal or arhythmic, which means that they can be as active at night as during the day. The reasons, which are complex, are discussed in the introduction, but the main theme of the book concerns the senses which have evolved to function equally well under the widely differing conditions of day and night. The echolocation of bats comes obviously to mind but it is, perhaps, not so well known that some birds, including those which provide the Chinese delicacy bird's-nest soup, also use this system of finding their way in the dark and locating their food. Even more usual senses such as sight and hearing have many refinements in nocturnal animals: higher sensitivity, methods of amplifying dim light by a mirror-like membrane behind the retina, and 'super ears', as the author calls them, which respond to a wider range of sounds than we can recognise.

Echolocation under water, the acute sense of smell possessed by sharks, the use of barbels and other taste organs by fish and the highly sensitive taste cavities in snakes, which give them a tracking power far superior probably to that of any other animals, are some of the fascinating subjects discussed. Particularly valuable is the very clear and detailed account of the functioning of the lateral line system of fish, which among other things enables them to swim in compact shoals with rapid changes of direction without colliding.

The text is illustrated by many photographs and bold if somewhat crude, diagrams.

JOHN CLEGG

\section{Waterfowl: Their Biology and Natural History by Paul A. Johnsgard. University of Nebraska Press, \$8.95.}

Paul Johnsgard is able to present to a non-specialist public the basic biological knowledge of waterfowl in a way that is eminently clear and understandable, arranged by subject rather than by species, and stressing biology and behaviour, the whole being freely illustrated by photographs both in black-and-white and colour. Of 142 living species, he has observed no fewer than 136 in life, and photographs of essentially all these species are included in what must be about the most comprehensive collection ever assembled for one book. It must be a great disappointment to him that the reproduction of those in black-and-white leaves much to be desired; many are far too dark, so that plumage details and contrast are lost. On the other hand the colour reproductions are excellent.

Without doubt Paul Johnsgard has succeeded in his most ambitious task. Among the subjects dealt with are distribution and migration; ecology and general behaviour; sound production; social behaviour, breeding biology; moults and plumages; evolution and hybridisation; waterfowl, man and the future. He pays a special tribute to the Wildfowl Trust, where he studied from 1959-61 
before returning to the USA to become Assistant Professor of Zoology at Nebraska: "were it not for that unrivalled collection of living waterfowl the present work could not have been written'.

Unlike Paul Johnsgard, very few of us can be experts in so wide a field. This is a book which will be of the greatest value to all who take an interest in waterfowl, specialist and non-specialist alike.

JEFFERY HARRISON

\section{Bird Navigation by G. V. T. Matthews. Cambridge UP, £2 cloth (15s. paperback).}

This new edition of a book published in 1955 contains 350 references to more recent literature, and the text has been completely rewritten; the result is "virtually a new book'. As before, it is a compact, lucid and authoritative presentation of a fascinating subject, to which the author's own experiments have made a valuable contribution.

Dr Matthews restricts the term 'navigation' to 'the ability to initiate and maintain directed movement independently of landmarks'. He opens by setting the problem in its context of field observations, including the use of such techniques as ringing and radar. The experimental evidence for the existence of bearing-and-distance navigation is then considered, with a summary of the results of translocation of migrants; and next the physical bases of one-direction navigation, by day and by night. A review of homing experiments follows.

Chapters 7-11 deal with theoretical explanations and with experiments designed to test these. There are theories of sensory contact with home and of inertial navigation; and theories of navigation by geophysical grids, astronomical grids, and a grid derived from the sun's co-ordinates. Two final chapters usefully discuss the limitations of the avian eye and considerations involved in 'blind" flying and perception of gravity, in the appreciation of time intervals, and in circadian rhythms. All in all, it is a satisfying exposition which leaves the reader poised in expectation of still further advances from the active work continuing in various countries.

\section{A. LANDSBOROUGH THOMSON}

\section{Eagles, Hawks and Falcons of the World by Leslie Brown and Dean Amadon. Two vols. Country Life, 15 gns.}

These long-awaited volumes arrived on my desk shortly after returning from East Africa, where I had seen several birds of prey in puzzling plumages. They immediately proved their worth by illustrating a very striking pale form of the tawny eagle, which $I$ have so far been unable to find in any other book. Visitors to East Africa will need no reminding of the headaches encountered in trying to separate tawny, steppe and some other large eagles, with their varied plumages, from the limited range of readily available illustrations. Leslie Brown has studied eagles and other birds of prey, in his native Scotland, during many years in Africa, and in his other wanderings from India to Trinidad; this book contains the fruits of long years in the field. And there can be few ornithologists who have been able to study the breeding habits of the crowned hawk-eagle from their sitting-room window, as he still can from his house at Karen near Nairobi.

But for the misfortune of a considerably inferior book appearing not long ago entitled Birds of Prey of the World, that would have been the appropriate title for this massive and authoritative work, which will surely remain the standard 